\title{
Programa Nacional Biblioteca da Escola (PNBE) - uma avaliação diagnóstica
}

\author{
Jane Paiva * e Andréa Berenblum **
}

Resumo: O presente trabalho apresenta, socializa e discute alguns resultados da pesquisa realizada em 2005/2006 em parceria com a Unesco, sobre o Programa Nacional Biblioteca da Escola (PNBE), da Secretaria de Educação Básica (SEB) do Ministério da Educação (MEC). A pesquisa buscou conhecer, por meio de uma amostra estatística, as concepçôes de livro, leitura, escrita e biblioteca de docentes, de alunos, de diretores e de comunidades de escolas públicas brasileiras envolvidas com o recebimento de acervos individuais e coletivos, no âmbito do Programa. A investigação constituiu uma avaliação diagnóstica acerca do funcionamento do PNBE que se centra, desde 1998, principalmente, na distribuição de obras literárias às escolas públicas. $\mathrm{O}$ trabalho apresenta não apenas algumas conclusões relativas aos impactos produzidos nas práticas pedagógicas e educativas a partir da política oficial de distribuição de livros, mas também as diversas formas de apropriação e implementação dessa política por parte dos diversos atores da escola envolvidos.

Palavras-chave: biblioteca da escola; livro e leitura; leitura literária.

\section{School Library National Program (PNBE) - a diagnostic assessment}

Abstract: This work presents, shares and discusses some of the outcomes of the research carried out in partnership with Unesco, in the years 2005/2006, focussing the School Library National Program (PNBE) developed by the Office of Basic Education (SEB), at the Brazilian Ministry of Education (MEC). By means of a statistical sample, the research attempted to reveal the teachers', the students', the school principals' and the Brazilian public school communities' representations of book, reading, writing and library. The Brazilian public schools participating in the research were those responsible for the reception of individual and group collections of books, within the scope of the Program. The investigation consisted of a diagnostic assessment focussed on the execution of the PNBE, which since 1998 has centered its activities mainly on the distribution of literary works to the public schools. The work offers a number of conclusions related to the impacts on the pedagogical and educational practices, which have been observed in connection with the official policies of book distribution, as well as the various ways in which such policies are assumed and implemented by several of the school agents involved in the process.

Key words: school library; reading book; literary reading.

\footnotetext{
* Professora Adjunta da Faculdade de Educação da Universidade do Estado do Rio de Janeiro (UERJ), Rio de Janeiro, Brasil. janepaiva@terra.com.br

* Professora Adjunta do Instituto de Educação da Universidade Federal Rural do Rio de Janeiro (UFRRJ), Rio de Janeiro, Brasil. andyblum@uol.com.br
} 


\section{Contextualizando a pesquisa}

A avaliação diagnóstica do Programa Nacional Biblioteca da Escola (PNBE), realizada no quarto trimestre de 2005, cujo relatório foi concluído em março de 2006, foi proposta pela Secretaria de Educação Básica (SEB) do Ministério da Educação (MEC), em parceria com a Unesco, financiadora formal da pesquisa. Esta avaliação nasceu não apenas do desejo da SEB de obter subsídios que alimentassem as definições sobre os rumos de uma política de formação de leitores, mas também da exigência do Tribunal de Contas da União (TCU) que, desde 2002, indicara ao governo Fernando Henrique Cardoso a necessidade de realizá-la, sem sucesso, após auditoria em escolas do país, para avaliar a eficiência dos investimentos feitos. Nessa auditoria, cujo Relatório traz informações perspicazes da análise dos auditores ? argutos nas observações quanto às práticas de leitura verificadas nas escolas em que estiveram e nas "montanhas" de livros estocados ?, indícios e fatos reais da problemática que o MEC deveria enfrentar já se anunciavam, mas não mobilizaram a equipe do Ministério que a recebeu. Só a partir de 2003 o Relatório do TCU passou a ser considerado, na (re)definição necessária a ser proposta para o Programa. Dados empíricos de várias partes do país somavam-se aos então levantados e exigiam uma pesquisa sistemática.

O significativo investimento realizado pelo governo federal, desde 1998, no Programa - integrado por vários subprogramas de distribuição de kits de livros com diferentes finalidades e objetivos - referiu-se essencialmente à aquisição e à distribuição de coleções de literatura e obras de referência para alunos e professores de escolas públicas de 3.659 municípios. O volume de obras distribuído e o investimento total realizado contrastavam, muitas vezes, principalmente quanto ao uso e ao destino dos livros e com a situação estrutural das escolas, fato demonstrado pela pesquisa. . Embora o Programa tivesse nascido com a finalidade de equipar as escolas com livros para as bibliotecas escolares, em acervos coletivos, em dado momento os investimentos destinaram-se a coleções pessoais recebidas por poucos alunos, em relação ao universo de matrículas. Praticamente, o PNBE manteve-se apenas como um grande programa de distribuição de livros, como se a existência de acervos (de qualidade) fosse o caminho natural de formação de leitores nas escolas públicas brasileiras, sem prever apoio algum a projetos de formação continuada de professores com o foco na leitura literária.

Negociado o projeto nacional de Avaliação Diagnóstica com a SEB, estabeleceu-se a finalidade de conhecer, a partir de amostra estatística, concepções e sentidos de livro, leitura, escrita, biblioteca que circulam na prática escolar, expressos pelos sujeitos atuantes nas escolas públicas. Ao mesmo tempo, pro- 
pôs-se conhecer as práticas escolares decorrentes da decisão política de implementação de um programa de distribuição de obras literárias individuais e coletivas, os impactos produzidos por essa política e como isso se expressava nas práticas pedagógicas.

A metodologia do projeto definiu não somente a realização da pesquisa por amostra, em escolas pertencentes a oito Unidades da Federação, abrangendo 19 municípios, distribuídos geograficamente, atendendo os resultados do Censo Demográfico de 2000, realizado pelo Instituto Brasileiro de Geografia e Estatística (IBGE), como também a cobertura de 467.275 escolas contempladas com as remessas dos livros integrantes do Programa Nacional Biblioteca da Escola (PNBE).

Optou-se por trabalhar a partir de uma amostra, porque esta constituía uma parcela convenientemente selecionada da população a ser estudada, e para isso se utilizou a técnica de amostra multiestágios (AM), recomendada por instituição especializada. Para compô-la, a população foi dividida em subpopulações, estas novamente divididas em subsubpopulaçôes e assim por diante, em vários estágios. Uma amostra aleatória foi selecionada em cada estágio para compor a amostra total. Por não requerer uma lista (cadastro) de todos os elementos constituintes da população, mas apenas listas de regiōes, estados, municípios, bairros, ruas, etc., este esquema de amostragem mostrou-se vantajoso. Mas, de todo modo, a AM requereu aplicação da regra de "probabilidade proporcional ao tamanho (PPT)" para garantir iguais probabilidades de os indivíduos serem selecionados na amostra.

A confiabilidade na coleta de dados, sem cometer erros de amostragem, foi garantida pelo fato de a amostra ter a mesma composição que a população, na sua totalidade. A validade assegurou-se pela formação dos pesquisadores e pelas informações dispensadas aos entrevistados quanto às questôes investigadas. Também se consideraram todas as escolas que receberam livros do Programa Literatura em minha casa ${ }^{1}$, por serem as mais indicadas para a avaliação, e identificou-se a população de 7 a 14 anos como sujeitos centrais da investigação ${ }^{2}$. Foram selecionadas 102 escolas nas capitais dos estados: Pará, na Regiāo Norte; Ceará, Sergipe e Bahia, na Região Nordeste; Minas Gerais e Espírito Santo,

1. O Programa Literatura em minha casa destinou-se, inicialmente, a crianças de $4^{a}$ série, estendendose logo aos de $5^{\mathrm{a}}$ e, no último ano de sua existência foi ampliado para adolescentes de $8^{\mathrm{a}}$ série e para jovens e adultos em etapa final do ensino fundamental. Este nível de ensino, garantido como direito de todos, independente da idade, é conquista constitucional desde 1988, e atualmente estendeu-se para nove anos.

2. Como o Programa foi destinado ao ensino fundamental, não foram excluídos os jovens e adultos beneficiados pelo PNBE em 2004 com a coleção Palavra da Gente, e sempre que encontrados projetos de educação de jovens e adultos nas escolas selecionadas, estes foram incluídos como sujeitos da pesquisa. 
na Região Sudeste; Rio Grande do Sul, na Região Sul; e Goiás, na Região Centro-Oeste. Outras 94 escolas foram selecionadas nos demais municípios, em um raio de até $100 \mathrm{~km}$. A seleção dos municípios em cada estado baseouse nos dois/três municípios com maior probabilidade, utilizando-se ainda o critério de condiçõoes de acesso, a saber: Ananindeua e Castanhal, no Pará; Caucaia, no Ceará; Lagarto, em Sergipe; Camaçari, na Bahia; Betim e Contagem, em Minas Gerais; Vila Velha, no Espírito Santo; Viamão e Canoas, no Rio Grande do Sul; Anápolis, em Goiás. Do conjunto de 196 escolas, 100 eram estaduais e 96 municipais, resultado da escolha aleatória da etapa de seleção.

Tabela I. Quadro amostral estágios I, 2 e 3 e quantitativo de escolas por município

\begin{tabular}{|c|c|c|c|}
\hline Regiões & Estados & Municípios & Escolas \\
\hline \multirow[t]{2}{*}{ Norte } & \multirow[t]{2}{*}{ Pará } & \multirow{2}{*}{$\begin{array}{l}\text { Belém-- } \\
\text { Ananindeua } \\
\text { Castanhal }\end{array}$} & 25 \\
\hline & & & 5 \\
\hline \multirow[t]{6}{*}{ Nordeste } & \multirow[t]{2}{*}{ Bahia } & \multirow{2}{*}{$\begin{array}{l}\text { Salvador } \\
\text { Camaçari }\end{array}$} & 15 \\
\hline & & & 9 \\
\hline & \multirow[t]{2}{*}{ Ceará } & \multirow{2}{*}{$\begin{array}{l}\text { Fortaleza } \\
\text { Caucaia }\end{array}$} & 17 \\
\hline & & & 15 \\
\hline & \multirow[t]{2}{*}{ Sergipe } & \multirow{2}{*}{$\begin{array}{l}\text { Aracaju } \\
\text { Lagarto }\end{array}$} & 6 \\
\hline & & & 4 \\
\hline \multirow[t]{2}{*}{ Centro-Oeste } & \multirow[t]{2}{*}{ Goiás } & \multirow{2}{*}{$\begin{array}{l}\text { Goiânia } \\
\text { Anápolis }\end{array}$} & 10 \\
\hline & & & 10 \\
\hline \multirow[t]{5}{*}{ Sudeste } & \multirow[t]{2}{*}{ Espírito Santo } & \multirow{2}{*}{$\begin{array}{l}\text { Vitória } \\
\text { Vila Velha }\end{array}$} & 5 \\
\hline & & & 7 \\
\hline & \multirow[t]{3}{*}{ Minas Gerais } & \multirow{3}{*}{$\begin{array}{l}\text { Belo Horizonte } \\
\text { Betim } \\
\text { Contagem }\end{array}$} & 12 \\
\hline & & & 9 \\
\hline & & & 9 \\
\hline \multirow[t]{3}{*}{ Sul } & \multirow{3}{*}{$\begin{array}{l}\text { Rio Grande do } \\
\text { Sul }\end{array}$} & \multirow{3}{*}{$\begin{array}{l}\text { Porto Alegre } \\
\text { Canoas } \\
\text { Viamão }\end{array}$} & 12 \\
\hline & & & 13 \\
\hline & & & 13 \\
\hline Total & 8 & 19 & 196 \\
\hline
\end{tabular}


Da pesquisa participou uma equipe nacional formada por profissionais com experiência na metodologia de grupo focal (seis doutores, três doutorandos, oito mestres, três mestrandos, uma antropóloga e uma licenciada em Pedagogia), eleito como instrumento metodológico para trabalhar com professores e alunos nas escolas selecionadas. Os pesquisadores vivenciaram dois momentos coletivos - o primeiro, em preparação à ida a campo e o segundo, no retorno, já com os relatórios de campo produzidos, visando a formular, coletivamente, reflexões sobre os achados e as questôes centrais emergentes da pesquisa, a serem discutidas no relatório final.

A metodologia adotada previu a coleta de dados em campo, a partir de quatro procedimentos: a) observação do campo; b) entrevistas com diretores, coordenadores pedagógicos, agentes de biblioteca (auxiliares, técnicos, responsáveis, bibliotecários); c) grupo focal com alunos e com professores; e d) entrevista com pais e membros da comunidade.

Todas as entrevistas e as diversas formas de abordagem metodológica foram precedidas de um roteiro previamente elaborado e de fichas de perfil dos sujeitos participantes, em todos os casos não-identificados. As observações de campo também foram realizadas a partir de um roteiro que incluía aspectos a serem verificados nas escolas. A metodologia de grupo focal (GF) seguiu um procedimento semelhante e, como técnica de investigação de abordagem qualitativa, exige certa homogeneidade na formação dos grupos - grupos integrados só por alunos ou professores, só de alunos de uma determinada série ou nível de ensino, em que todos receberam livros, etc. Ainda que os grupos representem recortes de grupos sociais determinados, não se estabelecem de forma aleatória, mas levando em conta o objeto focal, constituindo-se, por isso, como grupo homogêneo. Para o GF de alunos, estabeleceu-se a prioridade de estudantes de $5^{\mathrm{a}}$ a $8^{\mathrm{a}}$ séries que participaram do Programa (em alguma das modalidades, fosse individual ou coletiva) e contou-se com o caso de alguns alunos de nível médio, pelo fato de haverem recebido a coleção Literatura em minha casa no primeiro ano do Programa.

A opção metodológica por essa técnica grupal de coleta de concepções e opiniões, recomendada para avaliação de políticas públicas, fundamenta-se no fato de que favorece rápidas posiçôes a respeito de um tema. Por meio do GF todas as singularidades presentes e assumidas pelos participantes tendem a aparecer, sem que seja necessário revelar seus enunciadores. Por meio da interlocução que se estabelece entre os pares participantes do GF, chega-se à opinião do grupo como um todo. Por fim, a metodologia de GF conduz a categorias de análise comuns a todas as equipes e estados/municípios, ainda que seja possível agregar categorias novas surgidas a partir dos próprios grupos, o que exige atenção às particularidades de cada realidade investigada. 
Inúmeras dificuldades cercaram a realização dos grupos focais, algumas previamente estimadas, todas superáveis, o que não impediu o uso da metodologia, mas exigiu experiência dos investigadores. Observe-se a distribuição dos grupos focais realizados em todo o país:

Tabela 2: Número de grupos focais realizados com alunos e professores, por estado/município

\begin{tabular}{|c|c|c|c|}
\hline \multirow{2}{*}{$\begin{array}{l}\text { Estados/Municípios/ } \\
\text { sujeitos }\end{array}$} & \multicolumn{3}{|c|}{ Número de grupos focais realizados } \\
\hline & Alunos & Professores & Total \\
\hline Pará & 4 & 3 & 7 \\
\hline \multicolumn{4}{|l|}{$\begin{array}{l}\text { Belém/Ananindeua/ } \\
\text { Castanhal }\end{array}$} \\
\hline Ceará & 8 & 9 & 17 \\
\hline \multicolumn{4}{|l|}{$\begin{array}{l}\text { Fortaleza } \\
\text { Caucaia }\end{array}$} \\
\hline Sergipe & 7 & 7 & 14 \\
\hline \multicolumn{4}{|l|}{$\begin{array}{l}\text { Aracaju } \\
\text { Lagarto }\end{array}$} \\
\hline Bahia & 4 & 3 & 7 \\
\hline \multicolumn{4}{|l|}{$\begin{array}{l}\text { Salvador } \\
\text { Camaçari }\end{array}$} \\
\hline Minas Gerais & 6 & 6 & 12 \\
\hline \multicolumn{4}{|l|}{$\begin{array}{l}\text { Belo Horizonte } \\
\text { Betim } \\
\text { Contagem }\end{array}$} \\
\hline Espírito Santo & 8 & 4 & 12 \\
\hline \multicolumn{4}{|l|}{$\begin{array}{l}\text { Vitória } \\
\text { Vila Velha }\end{array}$} \\
\hline Rio Grande do Sul & 5 & 5 & 10 \\
\hline \multicolumn{4}{|l|}{$\begin{array}{l}\text { Porto Alegre } \\
\text { Canoas } \\
\text { Viamão }\end{array}$} \\
\hline Goiás & 4 & 3 & 7 \\
\hline \multicolumn{4}{|l|}{$\begin{array}{l}\text { Anápolis } \\
\text { Goiânia }\end{array}$} \\
\hline Total & 46 & 40 & 86 \\
\hline
\end{tabular}


Do ponto de vista quantitativo, a pesquisa abordou 359 alunos, 303 professores, 200 diretores, cinco bibliotecários, 152 responsáveis por bibliotecas e 31 pais, além de outros 37 profissionais das escolas, totalizando 1.087 pessoas em 196 escolas, em 19 municípios, de oito estados.

Ao tomar como referência a concepção de avaliação diagnóstica, teceu-se uma narrativa marcada pelas múltiplas vozes: dos pesquisadores, dos participantes envolvidos e de vários autores/interlocutores que estudam a problemática, capazes de revelar a multiplicidade de práticas de leitura, os variados sentidos que a ela se atribuem, a dimensão coletiva da discussão, com a perspectiva de analisar questôes que demonstrassem mudanças nas práticas locais, com vista à reformulação de políticas públicas na área.

A complexidade dos objetivos fixados para analisar atos de leitura e de escrita conduziu a equipe a modificar o tempo previsto para o desenvolvimento da pesquisa, considerando a quantidade de dados recolhidos e a sistematização em relatórios de campo e final e, conseqüentemente, a necessidade de aprofundar estudos teóricos, de modo a entrecruzar as múltiplas possibilidades explicativas sobre esses mesmos dados.

As reflexões coletivas às quais a investigação permitiu chegar possibilitaram o registro da complexidade, da pluralidade de ações e de soluçôes que marcam as práticas de leitura nos múltiplos espaços das escolas e de seu entorno, em uma tentativa de avançar no controle inicial de programas educativos, especialmente o PNBE. Isso contribuiu tanto na tomada de decisões acerca de seu destino, como na adoção de ações que, decorrentes da pesquisa, exijam reorientação ou revisão, como o caso de apoio a projetos de formação continuada de professores.

\section{O significado da leitura e da escrita como fundamento da pesquisa}

Todos os programas de leitura ou de incentivo à leitura fundamentam-se (implícita e explicitamente) em alguma concepção de leitura nem sempre vinculada a práticas sociais. Para identificar essas concepções e as diversas formas que orientam as práticas docentes, a pesquisa buscou diagnosticar os usos das obras literárias, suas diversas formas de distribuição entre os alunos; identificar os destinatários dos conjuntos de livros individuais e as práticas de leitura e de escrita existentes nas escolas investigadas.

A partir da década de 1980, registrou-se um aumento em nível mundial, e no Brasil em particular, de pesquisas acadêmicas que abordam a problemática da linguagem de diversas perspectivas teóricas e diferentes campos disciplinares. Esse desenvolvimento teórico, junto com o reconhecimento de que os acelerados avanços científicos e tecnológicos e as modificaçôes nos mapas culturais 
tradicionais impõem novas demandas sociais à educação, contribuíram para repensar os conceitos de alfabetização, leitura e escrita, a partir de novos desafios do mundo contemporâneo. Diversas investigações e debates acadêmicos vêm afirmando a necessidade de modificar práticas escolares de produção de textos e de formação de leitores, considerando os aspectos culturais e sociais que constituem esses processos. O conceito de alfabetismo começou a ser utilizado nos meios acadêmicos como tentativa de superar a concepção de alfabetização centrada nos aspectos tecnológicos (codificação e decodificaçãa) de aquisição da língua escrita. Vários autores - Kleiman (1995); Soares (2002); Rojo (1998); Tfouni (2002); Goulart (2001), entre outros, partindo de diversos paradigmas teóricos, dedicaram-se a definir o conceito de alfabetismo que envolve práticas sociais efetivas de leitura e de escrita. Um argumento em favor do uso do termo referia-se ao fato de que vários grupos sociais utilizavam a leitura e a escrita de forma diferenciada em relação a práticas sociais e culturais desses mesmos grupos.

A década de 1990 pode ser definida, no plano da política educativa, como uma época de instauração de uma cultura avaliativa. Ao mesmo tempo em que as autoridades educacionais locais criavam sistemas de avaliação quantitativa de habilidades e de competências individuais para as diversas áreas de conhecimento, estabeleciam-se parâmetros internacionais de avaliação de desempenho de estudantes que permitiam realizar comparaçōes entre os diversos países participantes. Essas orientaçôes, ditadas por agências de financiamento internacional, construíram metodologias e referências consoantes com o projeto neoliberal, que incluía a desqualificação da escola pública e a ausência de reconhecimento do multiculturalismo das diversas populaçôes, o que constitui seus universos culturais e simbólicos. Ao contrário, propunha-se um modelo único, pensado para supostos sujeitos homogêneos, a partir de paradigmas educativos de prestígio para a elite, como forma de resolver os problemas da desigualdade educacional. Esse modelo baseava-se em uma imagem de Estado inoperante e oferecia uma alternativa à educação pública: a privatização dos serviços educacionais. Essa alternativa fundamentava-se em um conjunto de instrumentos de avaliação que anulava a heterogeneidade, as diferenças e o debate acadêmico. Um exemplo de proposta de avaliação foi estabelecido, a partir de 2000, pelo Programa Internacional de Avaliação de Alunos (Pisa), da Organização para a Cooperação e Desenvolvimento Econômico (OCDE), cujo objetivo é medir o desempenho de alunos nas áreas de leitura, matemática e ciências. Em um primeiro momento, o Pisa centrou-se na avaliação de atitudes para a leitura; tendo participado, no caso brasileiro, 4.893 jovens entre 15 e 16 anos. Os resultados da avaliação mostraram que os países da América Latina ocuparam os últimos lugares e, entre estes, o Brasil localizou-se em último lugar. Os 
resultados mostraram que o desempenho de alunos brasileiros nas provas de leitura estava relacionado ao número de séries escolares concluídas. Entre os estudantes com nove ou mais anos de escolarização, a média nacional chegava a 431, em uma escala de 0 a 625. Quando tinham oito anos de estudo, a pontuação descia para 368 e, com sete anos, caía para 322. Esta diferença de pontuação levava a média geral a 396 e localizava o Brasil em último lugar na lista de avaliação, que incluía 28 nações desenvolvidas e quatro emergentes: Brasil, Letônia, México e Rússia.

Como interpretar esses resultados? O que indicavam? Quais seriam algumas das possíveis causas do baixo rendimento dos alunos brasileiros na área da leitura? Que críticas estão sendo realizadas ao modelo formulado?

Concordando com a análise crítica do Programa Pisa realizada por Emília Ferreiro (2005), não parecem existir padrões únicos e universais de avaliação eficientes para medir o desempenho de alunos em nenhuma área de conhecimento. Isso porque, como se sabe, existem enormes diferenças entre os países em relação às condiçôes de acesso a "conhecimentos e habilidades", considerados necessários para a plena participação social e, inclusive, como mostra o relatório do Programa Pisa, o Brasil é apresentado como um dos países com maior desigualdade na distribuição de renda e de bens culturais, e culturalmente diverso. Seria, então, possível medir competências, habilidades e rendimentos individuais com um único parâmetro de medida em país tão desigual e diverso?

Segundo Werthein (Correio Brasiliense, 10 abril 2005), ex-representante da Unesco no Brasil, calcula-se que $73 \%$ dos livros estão concentrados nas mãos de $16 \%$ da população e, segundo dados do IBGE, $89 \%$ dos municípios não possuem bibliotecas públicas e $65 \%$ não têm livrarias nem lojas de música. As bibliotecas bem equipadas estão localizadas em zonas urbanas e no centro de cidades. Dados obtidos a partir do Censo Escolar 2004, do Instituto Nacional de Estudos e Pesquisas Educacionais Anísio Teixeira (Inep), mostram que, das 53 mil bibliotecas escolares existentes em todo o país, 46 mil (86\%) estão localizadas em zonas urbanas, sendo que a rede privada concentra o maior número de bibliotecas escolares (39\% do total).

Essas estatísticas alarmantes mostram as enormes desigualdades regionais e a desigualdade na distribuição de bens culturais. A investigação realizada retratou a multiplicidade de dificuldades que enfrentam diretores e professores nas escolas brasileiras para estabelecer bibliotecas, para garantir funcionamento adequado às necessidades de professores e às demandas de alunos e para possibilitar acesso aos livros, assim como revelou o estado e a calamidade em que se encontravam os livros. 
Nos últimos anos a concepção de leitura tem sido repensada a partir de uma série de debates e trabalhos acadêmicos que a concebem como uma questão ao mesmo tempo pedagógica, lingüística e social (Orlandi, 1988). Autores como Geraldi, Lajolo, Zilberman, Soares, Goulart, Zaccur, entre outros, partindo de concepções teóricas diferentes, desenvolveram trabalhos que permitem conceber a leitura como atividade humana que implica algo mais que a decodificação e a compreensão de um sentido que está dado no próprio texto. A leitura implica, também, e, principalmente, a produção e a construção de sentidos, processo no qual o sujeito se constrói como leitor em interação com o texto, com outros textos, a partir de sua própria história de leitor e de suas experiências de vida. Considera-se, então, que o acesso a bens culturais é condição fundamental no processo de constituição do leitor, ao mesmo tempo que é essencial realizar um tipo de trabalho com a leitura que permita reflexionar acerca dessas relaçôes, dos sentidos apreendidos a partir do texto e dos sentidos produzidos e reconstruídos pelo leitor.

Analisados criticamente, os resultados do Pisa podem indicar que o tipo de trabalho realizado com a leitura nas salas de aula das escolas brasileiras é completamente diferente do requerido em provas de avaliação. Os dados recolhidos a partir do trabalho de campo da Avaliação Diagnóstica do PNBE necessariamente impõem reflexões sobre essas competências de leitura, porque, como se pôde constatar, o trabalho escolar baseia-se principalmente em livros didáticos, e é pouco freqüente o desenvolvimento de atividades com outros tipos de texto. A simples distribuição de livros nas escolas não mudará, portanto, as práticas pedagógicas em relação ao uso de livros de literatura nem a apropriação e a construção de novos sentidos a partir da leitura. Nos casos em que esses materiais são utilizados, o trabalho pedagógico continua marcado por uma forte tendência à decomposição de textos para o estudo de gramática prescritiva, em busca de respostas corretas e únicas interpretações para a leitura.

A democratização do acesso a obras literárias, esperado a partir da distribuição de livros com um amplo alcance em relação a usuários de diversos segmentos - alunos, professores e membros da comunidade - e com diversos desenhos - escolas e comunidade, kits de livros individuais e coletivos, obras e coleções - parece não ter sido alcançada. A disponibilidade de textos literários e de obras de referência na cultura escolar não é suficiente para transformar as práticas pedagógicas privadas e autoritárias instaladas nas escolas visitadas.

A disparidade entre o tipo de trabalho realizado com a leitura nas escolas e as capacidades e habilidades de leitura medidas nas avaliações internacionais - que implicariam o desenvolvimento de um trabalho escolar diferente com a língua escrita - tem sido confirmada por Ferreiro (2005, p. 39) que afirma, em relação aos programas de avaliação de rendimento: "tenemos [como resul- 
tado] evaluaciones individuales hechas con toda independencia de la evaluación de las condiciones que permitieron acceder a dichas competencias". Neste sentido, considera-se que a pesquisa desenvolvida pode constituir uma contribuição para conhecer o tipo de trabalho de leitura e de escrita efetivamente realizado nas escolas, auxiliando a interpretação crítica e produtiva dos resultados de programas de avaliação, questionando relaçôes, condiçôes de acesso e habilidades consideradas indispensáveis para que os sujeitos possam participar plenamente da vida em sociedade.

Não é mais possível admitir-se o desenho de políticas educativas sem enfrentar a problemática da extrema desigualdade social existente no país, sem avaliar a real oferta dos sistemas de ensino e das instituiçôes públicas e sem pensar nos professores como verdadeiros protagonistas da ação educativa. Às perversas condições de trabalho no cotidiano escolar e aos magros salários dos professores, quase nunca considerados, soma-se a responsabilidade pelos péssimos resultados obtidos pelos alunos nas provas de rendimento individual, aprofundando a penalização da profissão docente no Brasil.

A partir da investigação realizada pôde-se constatar a dificuldade dos professores para trabalhar com os livros distribuídos, a ausência quase total de formação que lhes permitisse reflexionar sobre sua prática pedagógica e discutir diferentes concepções de linguagem, de leitura e de escrita, os limites no aproveitamento do material disponível e a angústia pela falta de tempo para exercitar a própria leitura.

De posse dos fundamentos apresentados, destacaram-se oito categorias que permitiram compreender, de forma avaliativa, a realidade das ações e das práticas pedagógicas na sua complexidade, no que se refere ao uso e a significados da biblioteca e de obras literárias oferecidas.

As categorias emergentes do trabalho de campo foram as seguintes: 1) leitura e condiçốes sociais e culturais; 2) concepçôes de leitura e de escrita e de leitores; 3) espaços de leitura nas escolas; 4) crianças e adolescentes que nos escapam: eles não gostam de ler?; 5) atividades/práticas de leitura e currículo; 6) leitura como fundamento do projeto político-pedagógico (PPP) da escola; 7) os professores são leitores?; 8) formação docente para trabalhar com os livros; 9) formação de gestores para o trabalho com a leitura; 10) problematização de livros literários e didáticos; 11) práticas e atos de leitura; 12) publicidade de incentivo à leitura; 13) políticas de leitura e descontinuidades (participação local na escolha dos livros, inclusão de autores regionais, relação mais estreita do MEC com as escolas, investigação da realidade antes da implementação de Programas).

Em continuidade, portanto, detalham-se algumas compreensões, com vista a estabelecer diálogo sobre as principais questôes-objeto da pesquisa. 


\section{Sementes e semeadura}

Inicialmente, cabe destacar que a pesquisa foi responsável por um momento importante nas escolas, ao provocar o esforço dos entrevistados para reflexionar sobre os impactos do PNBE no cotidiano escolar desde a implantação da política de distribuição de acervos, sobre a qual demonstravam desconhecimento, principalmente no que se refere à fonte de financiamento das obras recebidas.

Nenhum programa de incentivo à leitura vinculado a políticas educativas, entretanto, pode subestimar as condições em que a educação escolar vem sendo realizada nas redes públicas brasileiras. $\mathrm{O}$ cotidiano das escolas visitadas, as condiçôes sociais em que estão inseridas definem o PNBE como uma ação cultural de baixo impacto nas políticas de formação do leitor e produtor de textos. Qualquer processo educativo que não seja capaz de renovar-se de acordo com as novas exigências impostas por desafios sociais, como é o caso da maior parte das comunidades abordadas durante a investigação, pode perder sua autenticidade e seu poder transformador.

Contraditória e singularmente, algumas escolas (inclusive as localizadas em bairros carentes e que funcionam em precárias condições físicas e humanas, que atendem desde crianças de primeiras séries do ensino fundamental até adultos), apesar de todos os obstáculos, contavam com guardiães e defensores da formação de leitores e produtores de textos. Mais além da limitação de espaço, demonstraram práticas interessantes e vívidas, transformando o impossível em espaço renovado, ativo, dinâmico e propício para a formação de alunos leitores e escritores.

A pesquisa e os pesquisadores foram recebidos de forma calorosa nas escolas, demonstrando interesse e motivação pela continuidade do Programa, ainda que denunciassem limitaçôes no uso dos livros disponíveis, destacando-se a utilização de obras de literatura para fins de pesquisa escolar e inúmeras dificuldades com a leitura e a escrita presentes em todas as escolas. A perspectiva de uma educação de qualidade suscita a busca do direito a dispor de materiais adequados para alunos e professores e em quantidade suficiente em relação ao uso requerido pelos estudantes. Associada a esta perspectiva, esteve sempre presente no discurso dos professores, ao avaliar o PNBE, a reivindicação por qualificação profissional, por formação e por remuneração que condigam com sua atividade. Um programa importante para a formação de bibliotecas nas escolas, de "eficácia operativa na distribuição de livros para as escolas beneficiadas” (TCU, 2002) não pode manter-se desvinculado das exigências de formação de professores, principais atores no incentivo e na dinamização da leitura de crianças e de jovens no espaço escolar.

Se para os investigadores e para o MEC a natureza específica de cada subprograma era um parâmetro importante da investigação, para os usuários 
entrevistados a nomenclatura das coleções era geralmente ignorada, prevalecendo outra lógica: a dos "livros da biblioteca". O sentido de pertencimento precário foi também fortemente observado e simbolizado pela chave que mantém fechada grande parte das bibliotecas escolares. O livro, como objeto, todavia parece ter o sentido sagrado que lhe deveria garantir perenidade, impossibilitando, dessa forma, a intimidade com o leitor e demonstrando uma concepção de apropriação como posse e pertencimento desse objeto.

No que se refere às concepçôes de biblioteca, existe geralmente uma ênfase nas características da estrutura física e uma separação entre esta e os projetos de incentivo à leitura. As escolas e a maioria dos professores, todavia, não desenvolveram uma análise compreensiva acerca das finalidades sociais das bibliotecas no interior das escolas, remetendo-se a enfoques unicamente didáticos, simplistas e alienadores. Uma concepção mais cuidadosa dos usos sociais da escrita e de suas implicaçôes no campo do desenvolvimento de sistemas de pensamento e de esquemas cognitivos mais amplos poderia considerar a potência geradora de conhecimentos que é a biblioteca, fonte de desenvolvimento da autonomia de pensamento e de criatividade e poderia, principalmente, tornála um instrumento indispensável na formação da identidade dos atores da escola e da comunidade.

Transparece em inúmeros depoimentos e ações apresentados pelos entrevistados a fragilidade da formação técnica dos profissionais que atuam na escola: professores, coordenadores, pedagogos e diretores, independentemente do tempo de formação de cada um e do nível de formação (magistério, formação universitária de graduação ou de pós-graduação). Além do nível de formação, do tempo e da experiência na docência ou na função exercida na escola, a insegurança, a ausência de interesse e de criatividade no uso dos recursos bibliográfi$\cos$ e da própria biblioteca foram características evidenciadas a partir da pesquisa.

O espaço da biblioteca escolar também pôde ser questionado. Em grande parte das escolas esse dispositivo não existe como tal, sendo substituído por salas de leitura, "cantinhos", etc. O desenho de bibliotecas nos projetos arquitetônicos das escolas é raro, inclusive quando foram projetadas como parte do edifício escolar, e a dinâmica institucional conduz ao "reaproveitamento" das bibliotecas como salas de aula, sempre que a escola pensa em expansão de matrícula. Pensar a biblioteca escolar com características físicas que transcendam a idéia de uma sala com estantes de livros não foi o denominador comum nas escolas visitadas. Pelo contrário, muitas bibliotecas se confundiam com depósitos de livros amontoados sem nenhum critério nem organização e, muitas vezes, encontraram-se os livros empacotados em suas embalagens originais. Outras se reduziam a "armariotecas", os livros encontravam-se guardados em 
armários trancados a chave, indisponíveis para consulta de alunos ou de professores. Em muitas bibliotecas não existiam registros dos livros em catálogos, o que implicava desconhecimento por parte da comunidade escolar sobre a quantidade e a qualidade das obras de que dispunham.

Do ponto de vista do profissional que atua nas bibliotecas, registrou-se a inexistência quase total de bibliotecários com formação, a ausência de cursos que qualifiquem os responsáveis para a função e a pouca valorização da problemática do livro, da leitura e da biblioteca no currículo da maioria dos cursos de formação. A figura mais comum encontrada neste espaço é a do "professor readaptado", ou seja, deslocado da função de regente de turma por problemas de saúde.

Nos casos em que foi possível avaliar precisamente os livros disponíveis correspondentes aos diversos subprogramas do PNBE, estes foram considerados de boa qualidade pela maioria dos participantes da avaliação diagnóstica, o que justificaria a permanência do envio de livros às escolas.

Resulta impostergável que os diferentes sistemas de ensino estabeleçam políticas de leitura que repercutam fora dos muros da escola, nas famílias e nas comunidades de origem dos alunos. O PNBE estimulou as esferas municipais e estaduais de administração da educação a se mobilizarem para aplicar recursos na aquisição de livros para as bibliotecas escolares.

Houve, sem dúvida, algumas mudanças a partir da implementação dos Programas, que se referem a uma implicação maior dos alunos com a leitura, indicada pela visita mais freqüente às bibliotecas ou a salas de leitura das escolas. De forma contrária à atitude de muitos professores, os alunos demonstraram concepçôes claras de leitura e de escrita e de sua importância para a vida, revelando grande interesse por diferentes práticas de leitura. Muitos desses alunos são oriundos de famílias em que os pais e as mães são analfabetos.

A ausência de uma política de formação de leitores e de esclarecimentos suficientes sobre as finalidades educativas do PNBE favoreceu a ambigüidade que se percebeu nas escolas, a falta de diferenciação entre livro didático, obra de referência e livro de literatura. A lógica que se destaca no uso de obras literárias deixa de valorizar o lúdico, a fantasia, a imaginação, para incentivar o conhecimento de características dos gêneros literários, nos moldes escolares. Ainda que a literatura para as idades correspondentes à escola de nível fundamental esteja dirigida a crianças, a adolescentes e a jovens e embora se constate que na prática escolar se desenham as marcas que definem gostos, interesses, escolhas, sonhos, modos de perceber a realidade e as possíveis diversas formas de interagir com esta, esses sujeitos restam, somente, na categoria aluno. Isso mantém uma suposta homogeneidade entre eles e deixa de contemplar a riqueza das experiências que os alunos vivenciam que, mediadas pelos textos 
literários, podem ser ressignificadas.Descontinuidade nas gestões e informaçôes que não circulam de um mandato ao outro, falta de afinidade com registros e documentos escritos que narram a história escolar foram consideradas atitudes responsáveis pelo desconhecimento bastante generalizado quanto à existência e às características do PNBE.

Apesar das diversas questóes levantadas - que voltam a ser consideradas sementes para, novamente fertilizar o campo em que podem germinar - a pesquisa demonstrou o reconhecimento de que as coleções estão produzindo importantes impactos de incentivo à formação de leitores, ainda que seja necessário dedicar tempo e recursos para a realização de acompanhamento desses resultados e novas avaliaçôes.

Ao se finalizar uma avaliação como esta, é indispensável formular novas questôes suscitadas pela realidade do campo investigado e reflexōes dela resultantes: como pensar políticas de leitura que não se restrinjam ao espaço escolar, inclusive reconhecendo sua importância para a formação do estatuto de leitor? Como envolver diferentes segmentos sociais para a definição de políticas públicas? Não se estará correndo o risco de valorizar o livro como único suporte de leitura, desconsiderando os demais? Não se estaria idealizando a infância ao não se considerarem novas formas de leitura? Que concepçōes de leitura devem fundamentar a formação de professores? Como melhorar o baixo nível de leitura dos estudantes e de seus professores nas escolas investigadas? Como encarar a falta de professores, bibliotecários, técnicos de biblioteca e outros atores pedagógicos que possam facilitar a rede de leitura e de produção textual, não somente no ensino fundamental, mas, também, e principalmente, na educação de jovens e adultos, tão relegada ao segundo plano? Propôe-se pensar, discutir e reflexionar sobre estas questôes, à luz dos dados coletados na pesquisa, promovendo o debate e o intercâmbio com equipes de pesquisadores que abordem problemáticas afins em outros contextos analisados.

\section{Referências bibliográficas}

BRASIL. IBGE. Disponível em <www.ibge.com.br/cidadesat/dedafault..php.> Acesso em 02/12/2005.

BRASIL. Tribunal de Contas da União. Avaliação do Programa Nacional Biblioteca da EscolaPNBE. Sumário Executivo. Brasília, 2002. Disponível em pdf.

FERREIRO, Emília. La internacionalización de la evaluación de los aprendizajes en la educación básica. Revista Avance y Perspectiva — Centro de Investigación y de Estudios Avanzados del Instituto Politécnico Nacional. México DF, n. 24. enero/mar. 2005.

GERALDI, João Wanderley. Portos de passagem. São Paulo: Martins Fontes, 1999. 
GOULART, Cecília Maria Aldigueri. Alfabetização, letramento e práticas pedagógicas. Cadernos de Ensaios e Pesquisas do Curso de Pedagogia da Uff, Niterói, Rio de Janeiro, v. 1, p. 75-78, 2001.

KLEIMAN, Angela. Os significados do letramento. Uma nova perspectiva sobre a prática social da escrita. Campinas: Mercado de Letras, 1995.

ORLANDI, Eni. Discurso e leitura. São Paulo: Cortez, 1988.

ORLANDI, Eni. O inteligível, o interpretável e o compreensível. In: ZILBERMAN, Regina; SILVA, Ezequiel Teodoro da. Leitura: perspectivas interdisciplinares. São Paulo: Ática, 1988.

ROJO, Roxane. Alfabetização e letramento; perspectivas lingüísticas. Campinas, São Paulo: Mercado das Letras, 1998.

SOARES, Magda. As condiçōes sociais da leitura: uma reflexão em contraponto. In: ZILBERMAN, Regina; SILVA, Ezequiel Teodoro da. Leitura: perspectivas interdisciplinares. São Paulo: Ática, 1988.

SOARES, Magda. A reinvenção da alfabetização. Revista Presença Pedagógica. Belo Horizonte, jul./ago. 2003.

SOARES, Magda. Letramento: um tema em três gêneros. Belo Horizonte: Autêntica, 2002.

TFOUNI, Leda Verdiani. Letramento e alfabetização. São Paulo: Cortez, 2002. (Coleção questôes da nossa época).

WERTHEIN, Jorge. Viva(mos) a leitura. Correio Braziliense. Brasília, 10 de abr. 2006. Disponível em <www.unesco.org.br $>$.

Recebido em 18 de setembro de 2008 e aprovado em 11 de dezembro de 2008. 